\title{
Cerebral amyloid angiopathy in dementia and old age
}

\author{
MARGARET M ESIRI, G K WILCOCK* \\ From the Departments of Neuropathology and Geriatric Medicine, Radcliffe Infirmary, Oxford, UK
}

SUMMARY A necropsy study of 159 elderly patients drawn mainly from a prospectively assessed geriatric hospital population was carried out to investigate the relationship of cerebral amyloid angiopathy to Alzheimer's disease, other CNS disease and ageing. About half the patients were demented and the majority of these had Alzheimer's disease. In Alzheimer's disease there was an incidence of cerebral amyloid angiopathy of $82 \%$. Among the other groups of patients, both demented and non-demented, the incidence of cerebral amyloid angiopathy was a little over $30 \%$, and remained constant between 60 and 102 years of age.

Congophilic change, principally affecting small leptomeningeal and intracortical vessels, was first described by Scholz ${ }^{1}$ and is generally recognised to occur more commonly in old age and particularly in patients suffering from dementia due to Alzheimer's disease. Cerebral amyloid angiopathy has also been recognised to be a cause of intracerebral haemorrhage. This has been described as a familial disease in young and middle aged people ${ }^{2}$ and as a sporadic occurrence in the elderly. ${ }^{6-13}$ Cerebral amyloid angiopathy also occurs in association with atypical plaques in the brain in rare cases of progressive dementia or other neurological diseases as reported first by Worcester-Drought et $\mathbf{a l}^{\mathbf{3} 4}$ and reviewed by Griffiths et al. ${ }^{5}$

We report here a necropsy study drawn mainly from local geriatric and psychiatric Oxford hospital populations of 159 predominantly elderly patients in which we related the incidence of cerebral amyloid angiopathy to the clinical state of the patients and the other pathological findings in the central nervous system. All but 10 of these cases were prospectively assessed for the presence or absence of dementia. Some of them have been included in earlier reports on the frequency of argyrophilic plaques and neurofibrillary tangles, ${ }^{14}$ cell loss in the nucleus basalis $^{15}$ and CSF proteins ${ }^{16}$ in Alzheimer's disease.

*Present address: Department for Care of the Aged, . Frenchay Hospital, Bristol, UK.

Address for reprint requests: Dr MM Esiri, Department of Neuropathology, Radcliffe Infirmary, Oxford OX26HE, UK.

Received 23 July 1985 and in final revised form 30 January 1986. Accepted 8 March 1986

\section{Materials and methods}

\section{Cases studied}

A total of 159 cases was studied. In all except 10 cases a simple formal assessment of mental state was carried out in the 6 months before death using the Kew test ${ }^{17}$ or Mental Test Score. ${ }^{18}$ On the basis of clinical findings and the performance on these tests 82 of these patients were found to be demented and 67 non-demented. Ten patients were assessed clinically and of these four were judged to be demented and six undemented.

\section{Neuropathology}

A full necropsy was carried out in all cases and the brain fixed by suspension in $10 \%$ neutral formalin for at least 4 weeks. In some cases one cerebral hemisphere was removed before fixation and stored at $-70^{\circ} \mathrm{C}$ for separate biochemical studies. All histological studies were performed on blocks from one fixed cerebral hemisphere. Paraffin blocks were taken from each of the main cerebral lobes and hippocampus from the first 73 cases in the series and from frontal and temporal lobes and hippocampus only from the succeeding 86 cases. The sections examined were from the following areas: superior and middle frontal gyri (Brodmann areas 9 and 46), superior and middle temporal gyri (Brodmann areas 22 and 21), area 7 of the parietal lobe and areas 17 and 18 of the occipital lobe. The hippocampus was examined in one section taken at or behind the level of the lateral geniculate nucleus. Cases in the different clinical and pathological categories were equally distributed among the first 73 and the later 86 cases. Amyloid was detected in $10 \mu \mathrm{m} \mathrm{sec}-$ tions stained with Congo Red. A total of 338 Congo Redstained sections of cortex from demented subjects and 285 from undemented subjects was examined. Adjacent sections were stained with haematoxylin and eosin, luxol fast blue and cresyl violet, and a modified Palmgren stain to show neurofibrillary tangles. ${ }^{19}$ Formalin-fixed $25 \mu \mathrm{m}$ frozen sections taken from adjacent regions of the cerebral hemispheres were stained by von Braunmühl's method for argyophilic plaques. 
Table 1 Summary of patients

\begin{tabular}{|c|c|c|c|c|}
\hline Disease category & No of cases & $\begin{array}{l}\text { Age (yr) } \\
\text { Mean (range) }\end{array}$ & $\begin{array}{l}\text { Percentage with } \\
\text { cerebral amyloid } \\
\text { angiopathy }\end{array}$ & $\begin{array}{l}\text { Percentage with extensive } \\
\text { cerebral amyloid } \\
\text { angiopathy }\end{array}$ \\
\hline \multicolumn{5}{|c|}{$\begin{array}{l}\text { Demented } \\
\text { Alzheimer's disease } \pm \text { cerebrovascular disease }\end{array}$} \\
\hline $\begin{array}{l}\text { Demented } \\
\text { Cerebrovascular disease }\end{array}$ & 18 & $81(66-95)$ & $33 \%$ & $7 \%$ \\
\hline $\begin{array}{l}\text { Demented } \\
\text { Other causest }\end{array}$ & 23 & $82(70-97)$ & $35 \%$ & $7 \%$ \\
\hline $\begin{array}{l}\text { Nondemented } \\
\text { No CNS disease }\end{array}$ & 26 & $81(66-91)$ & $27 \%$ & 0 \\
\hline $\begin{array}{l}\text { Nondemented } \\
\text { Cerebrovascular disease }\end{array}$ & 32 & $80(65-102)$ & $31 \%$ & $9 \%$ \\
\hline $\begin{array}{l}\text { Nondemented } \\
\text { With other CNS } \ddagger \text { disease }\end{array}$ & 15 & $80(60-92)$ & $46 \%$ & 0 \\
\hline
\end{tabular}

* Cerebral infarction in 11.

Small old cerebral infarct and old contusions in 1.

Small inactive multiple sclerosis plaques-1.

Additional pathology suggestive of Pick's disease-1.

tParkinson's disease-9.

Hydrocephalus -4 .

Probable Pick's disease-1.

Alcoholism with no specific CNS pathology-2.

No specific CNS pathology other than few plaques and tangles-7.

tParkinson's disease- 6 .

Hydrocephalus -1 .

Old contusions - 1 .

Epilepsy with no specific CNS pathology-1.

Depression with no specific CNS pathology-3.

Alcoholism with no specific CNS pathology-2.

Loss of consciousness with no specific CNS pathology-1.

The sections were number coded and examined without knowledge of the clinical findings. Congo Red-stained sections were examined first in an attempt to exclude bias introduced by knowledge of plaque and tangle content of adjacent sections since these easily identified the category of many cases. Exclusion of bias could not be total as the Congo Red-stained sections themselves allowed visualisation of some neurofibrillary tangles and plaques. The amount of vascular amyloid deposition in leptomeningeal and cortical vessels in each section was scored on a scale; absent 0 ; trace or occasional vessels affected 1 ; several vessels affected 2; the majority of vessels affected 3 . The prevalence of argyrophilic plaques and neurofibrillary tangle formation was similarly scored 0-3.

\section{Results}

On the basis of clinical and pathological findings the patients with dementia were divided into 3 groups (table 1); those with Alzheimer's disease, with or without cerebrovascular disease (45 cases), those with dementia due to cerebrovascular disease (18 cases) and those with another cause or an unidentifiable cause for their dementia ( 23 cases). The diagnosis of Alzheimer's disease was made in demented subjects if there were moderate or large numbers of argyrophilic plaques in the neocortex and at least a few neurofibrillary tangles in the neocortex as well as more numerous tangles in the hippocampus. The patients who were non-demented were divided into three groups: those with no central nervous system disease ( 26 cases), those with cerebrovascular disease (32 cases), and those with other diseases affecting the central nervous system (15 cases) (table 1$)$. All groups were closely comparable for age. Sex ratios in the var-

Table 2 Prevalence of cerebral amyloid angiopathy in all groups of patients according to age and sex

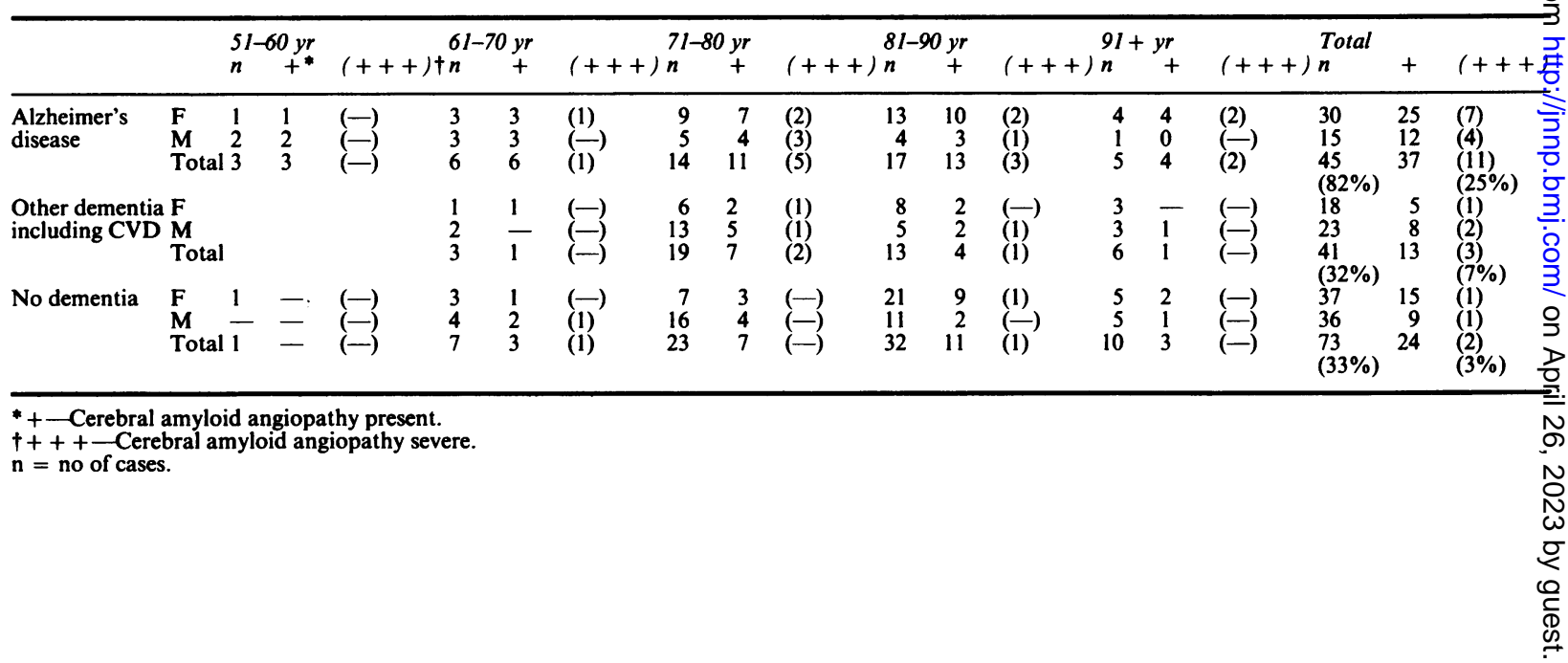


Table 3 Relationship of cerebral amyloid angiopathy to overall severity of pathology in cases of Alzheimer's disease

\begin{tabular}{llll}
\hline & Total & $\begin{array}{l}\text { Cerebral amyloid } \\
\text { angiopathy absent }\end{array}$ & $\begin{array}{l}\text { p value for } \\
\text { comparison }\end{array}$ \\
\hline $\begin{array}{l}\text { Cases with severe } \\
\text { pathology* }\end{array}$ & 21 & 1 & $\begin{array}{l}\text { p < }<0.05 \\
\text { (Fisher's } \\
\text { exact test) } \\
\text { pathologyt }\end{array}$ \\
\hline
\end{tabular}

${ }^{*}$ Combined plaque and tangle score $5 / 6$ or $6 / 6$.

tCombined plaque and tangle score $3 / 6$ or $4 / 6$.

ious groups differed somewhat with a preponderance of females in the Alzheimer's disease group and a smaller preponderance of males in the groups with CNS disease other than Alzheimer's disease or cerebrovascular disease. Observations on cases in each group were analysed in relation to age and sex. For some purposes of comparison the Alzheimer's disease group was compared with groups formed of all other causes of dementia and all non-demented groups. Comparisons were made using Yates' modification of the chi-square test or Fisher's exact test as appropriate.

\section{(1) Incidence of cerebral amyloid angiopathy by} disease group, age and sex (table 2)

Cerebral amyloid angiopathy was found to be much more common in Alzheimer's disease than in the other groups. Overall $82 \%$ of cases of Alzheimer's disease demonstrated at least a trace of amyloid deposition in vessels whereas both the other demented and nondemented groups showed amyloid deposition in $32 \%$ and $33 \%$ respectively. Severe cerebral amyloid angiopathy was seen in $25 \%$ of the Alzheimer's disease cases, in $7 \%$ of other dementia cases and in only $3 \%$ of nondemented controls. The severity of cerebral amyloid angiopathy in Alzheimer's disease was not directly related to the severity of plaque and tangle formation but cases of Alzheimer's disease with severe pathology were less likely than those with mild pathology (mainly more elderly patients) to have no cerebral amyloid angiopathy $(\mathrm{p}<0.05)$. Thus, only $5 \%$ of those with severe Alzheimer's disease pathology lacked any cerebral amyloid angiopathy whereas $29 \%$ of those with milder Alzheimer's disease pathology lacked cerebral amyloid angiopathy (table 3 ). The presence of cerebral amyloid angiopathy and its severity in Alzheimer's disease showed no correlation with the presence of cerebral infarction (table 4). Cerebral infarction was more common in Alzheimer's disease in those who were aged 81 and over $(41 \%)$ than in those aged 80 and under (13\%). In most cases it was attributable to a number of identifiable causes including in situ or embolic vascular occlusion associated with atheroma and arteriolar hyaline thickening, the latter usually associated with hypertension. In two cases only there were multiple small cortical infarcts in patients with cerebral amyloid angiopathy and no other identified significant cerebrovascular disease.

In the non-Alzheimer's disease groups, no clear increase in incidence of cerebral amyloid angiopathy with age was apparent, between the ages of 60 and 102 (table 2). Thirty-four per cent of those aged 80 years or under at death showed some cerebral amyloid angiopathy and this was true of $32 \%$ of those aged 81 years or more at death. Extensive amyloid deposition outside Alzheimer's disease was too uncommon for its relationship to age to be investigated. No clear correlation of cerebral amyloid angiopathy with sex among either Alzheimer's disease or other cases was found (table 2).

\section{(2) Location of cerebral amyloid angiopathy}

The location of cerebral amyloid angiopathy in all categories of patients was similar. Congophilic change, in the mildest form, affected small patches of the media of small arteries. These patches appeared as incomplete segments in transversely sectioned vessels. In longitudinal sections short lengths of the vessel wall were seen to be affected. When it was a little more advanced the adventitia was also infiltrated by congophilic material and the whole vessel circumference was involved. The full thickness of the vessel wall was affected in the most severe cases. Among the leptomeningeal vessels there was a subjective impression that cerebral amyloid angiopathy was found more commonly at the depths of sulci than at the crowns of gyri, but we are not certain whether this observation was simply a reflection of the greater density of vessels in sulci or whether it represents an increased frequency of cerebral amyloid angiopathy in sulcal vessels. No regular predilection for involvement of leptomeningeal or cortical vessels was observed. Vessels in subcortical and deep white matter were invariably spared. Basal ganglia and brain stem, in the few cases in which they were examined histologically for amyloid, did not show cerebral amyloid angiopathy, but the cerebellar leptomeningeal and cortical vessels were noted to be involved in some cases. There were only slight and insignificant differences in incidence of cerebral amyloid angiopathy between the main cerebral lobes when this was examined in cases from

Table 4 Relationship of cerebral infarction in Alzheimer's disease to presence of cerebral amyloid angiopathy

\begin{tabular}{lll}
\hline & $\begin{array}{l}\text { Cerebral infarction } \\
\text { present }\end{array}$ & $\begin{array}{l}\text { Cerebral infarction } \\
\text { absent }\end{array}$ \\
\hline $\begin{array}{l}\text { Cerebral amyloid } \\
\text { angiopathy present }\end{array}$ & 10 (severe in 3) & 27 (severe in 8) \\
$\begin{array}{c}\text { Cerebral amyloid } \\
\text { angiopathy absent }\end{array}$ & 2 & 6 \\
\hline
\end{tabular}


Table 5 Prevalence of congophilic angiopathy by lobe

\begin{tabular}{|c|c|c|c|c|c|c|}
\hline Age (yr) & $n$ & Frontal & Temporal & Parietal & Occipital & Hippocampus \\
\hline $\begin{array}{l}51-60 \\
61-70 \\
71-80 \\
81-90 \\
91-102 \\
\text { Total }\end{array}$ & $\begin{array}{r}4 \\
10 \\
24 \\
27 \\
8 \\
73\end{array}$ & $\begin{array}{r}2 \\
13 \\
14 \\
4 \\
38\end{array}$ & $\begin{array}{r}2 \\
5 \\
12 \\
8 \\
2 \\
30\end{array}$ & $\begin{array}{r}2 \\
6 \\
13 \\
8 \\
3 \\
33\end{array}$ & $\begin{array}{r}3 \\
7 \\
13 \\
12 \\
3 \\
38\end{array}$ & $\begin{array}{l}0 \\
0 \\
2 \\
1 \\
1 \\
4\end{array}$ \\
\hline
\end{tabular}

which sections of all lobes were available for study. In eight cases with minimal cerebral amyloid angiopathy affecting only one lobe the lobes involved were occipital lobe in three cases, parietal lobe in two cases, frontal lobe in two cases and temporal lobe in one case. The hippocampus was however markedly less affected by cerebral amyloid angiopathy (difference from other lobes $p<0.001$ ). In only four cases were hippocampal vessels affected by cerebral amyloid angiopathy and in all these cases leptomeningeal and neocortical vessels in all lobes were severely affected (Table 5). With regard to the validity of prevalence figures for cerebral amyloid angiopathy in the cases in which only frontal and temporal lobes and hippocampus were examined, we found that among the 73 cases in which all lobes were examined there were three cases in which cerebral amyloid angiopathy was evident only in parietal and/or occipital lobes. Two of these were cases of Alzheimer's disease and one a nondemented control. Prevalence figures in the whole series are therefore unlikely to underestimate the incidence of cerebral amyloid angiopathy in either Alzheimer's disease cases or others by more than $5 \%$.

\section{Discussion}

This series of cases of elderly demented and nondemented patients shows the already well established close correlation of cerebral amyloid angiopathy with Alzheimer's disease. Our finding of cerebral amyloid angiopathy in $82 \%$ of cases of Alzheimer's disease is not as high as in some series [for example Glenner, ${ }^{20}$ (92\%); Mandybur, ${ }^{21}(87 \%)$ ], but higher than in others [Jellinger, ${ }^{6}(78 \%)$; Mountjoy et al ${ }^{22}(60 \%)$ ]. It should be noted that not all authors have been convinced of an association between cerebral amyloid angiopathy and Alzheimer's disease, for example, Torack $^{23}$ claimed to find cerebral amyloid angiopathy in only a minority of cases of Alzheimer's disease. To some extent these variations may reflect the age of the patients studied, the severity of the pathology present, the diligence with which amyloid is sought, the extent of the sampling and the staining methods used. We found little difference in incidence of cerebral amyloid angiopathy between the main cerebral lobes but the hippocampus was spared except in a few cases with very extensive deposition in cerebral leptomeningeal and cortical vessels elsewhere. Mandybur ${ }^{21}$ and Glenner ${ }^{20}$ also found relative sparing of vessels in the hippocampus in cerebral amyloid angiopathy. We agree with Morimatsu $e a^{24}$ and Mandybur ${ }^{21}$ that the media is the first region of the vessel wall to become affected by amyloid deposition in cerebral amyloid angiopathy. We found that the prevalence of cerebral amyloid angiopathy in elderly patients without Alzheimer's disease was fairly constant at just over $30 \%$ regardless of the other clinical and pathological conditions present (cerebrovascular disease with or without dementia, other CNS disease including Parkinson's disease with or without dementia, hydrocephalus, alcoholism, depression, no CNS disease). As the prevalence was no higher in our cases of cerebrovascular disease (none of which were cases of intracerebral haemorrhage), than in the other non-Alzheimer's disease groups, the presence of cerebral amyloid angiopathy would appear not to be a contributory factor in major cerebral infarction as it appears to be for intracerebral and subarachnoid haemorrhage. ${ }^{6-13}$ A small group of six mildly demented non-Alzheimer's disease patients had a higher prevalence of cerebral amyloid angiopathy $(66 \%)$ than the rest of the nonAlzheimer's disease groups. Four of these patients showed no CNS pathology other than mild or moderate numbers of widespread argyrophilic plaques with or without some hippocampal neurofibrillary tangles. These can possibly be regarded as mild cases of Alzheimer's disease and as such would be expected to have the higher prevalence of cerebral amyloid angiopathy. They were not classified as such here because the extent of plaque and tangle formation was no more than that seen in some non-demented cases. In cases without Alzheimer's disease there was no clear increase in prevalence of cerebral amyloid angiopathy between the ages of 60 and 102 years. This contrasts with a successive increase in prevalence in each decade from 60-97 years in the study reported by Vintners and Gilbert. ${ }^{25}$ It would be of considerable interest to know whether the $30 \%$ or so of nondemented elderly patients with cerebral amyloid angiopathy are at risk of developing Alzheimer's disease. 
It remains tantalisingly difficult to develop a comprehensive hypothesis to explain the relationship of cerebral amyloid angiopathy to Alzheimer's disease. Glenner ${ }^{20}$ takes the view that "cerebrovascular amyloidosis is a significant if not the most significant lesion in Alzheimer's disease", and claims that his findings "strongly support a vascular basis for the other lesions in Alzheimer's disease". This view is difficult to reconcile with the regular finding in several studies already referred to, in addition to our own, of a small proportion of Alzheimer's disease patients that lacks cerebral amyloid angiopathy, and of a sizeable minority of undemented patients without Alzheimer's disease pathology who show it. Possibly there is a primary alteration which remains undefined and which in most instances, but not all, gives rise to both cerebral amyloid angiopathy and Alzheimer's disease. Results of pathological studies to date, including the present one, seem more compatible with the view that vascular amyloid is derived from a neural source within the brain and is a consequence of pathological processes going on there rather than the primary cause of those changes. If amyloidcontaining senile plaques reflect abnormal alterations of axonal terminals in the cerebral cortex it seems reasonable to wonder if vascular amyloid reflects abnormalities in nerve terminals innervating leptomeningeal and cortical blood vessels. The detection of neurofilament antigents in the amyloid deposits in cerebral amyloid angiopathy ${ }^{26}$ lends support to this view. It also seems likely that cerebral amyloid angiopathy has several causes of which one is Alzheimer's disease or the process that gives rise to Alzheimer's disease, and another is $\gamma$ trace protein deposition as seen in the Icelandic familial cases. ${ }^{27}$ It will be important to search for abnormal proteins in serum and CSF as well as in the cerebral vessels in cases of Alzheimer's disease with cerebral amyloid angiopathy if an analogy can be drawn with familial Icelandic cerebral amyloid angiopathy in which abnormal $\gamma$ trace protein levels in CSF have recently been reported. ${ }^{28}$

We are grateful to our colleagues in the departments of Geriatric Medicine and Psychiatry for referring cases for examination and to Mr Rowland Cross for technical assistance. Financial support was provided by the Medical Research Council.

\section{References}

${ }^{1}$ Scholz W. Studien zur Pathologie der Hirngefasse II. Die drusige Entartung der Hirnarterien und capillarien. $Z$ Ges Neurol Psychiat 1938;162:694-715.

${ }^{2}$ Gudmundsson G, Hallgrimmsson J, Jonasson TA, Bjarnason $O$. Hereditary cerebral haemorrhage with amyloidosis. Brain 1972;95:387-404.
${ }^{3}$ Worcester-Drought C, Greenfield JG, McMenemey WH. A form of familial presenile dementia with spastic paralysis. Brain 1940;63:237-54.

${ }^{4}$ Worcester-Drought C, Greenfield JG, McMenemey WH. A form of familial presenile dementia with spastic paralysis. Brain 1944;67:38-43.

${ }^{5}$ Griffiths RA, Mortimer TF, Oppenheimer DR, Spalding JMK. Congophilic angiopathy of the brain: a clinical and pathological report on two siblings. $J$ Neurol Neurosurg Psychiatry 1982;45:396-408.

6 Jellinger K. Cerebrovascular amyloidosis with cerebral haemorrhage. J Neurol 1977;214:195-206.

${ }^{7}$ Lee S-S, Stemmermann GN. Congophilic angiopathy and cerebral haemorrhage. Arch Pathol Lab Med 1978;102:317-21.

${ }^{8}$ Mandybur TI, Stephen RD, Bates MD. Fatal massive intracerebral haemorrhage complicating cerebral amyloid angiopathy. Arch Neurol 1978;35:246-8.

${ }^{9}$ Okazaki H, Reagan TJ, Campbell RJ. Clinicopathological studies of primary amyloid angiopathy. Mayo Clin Proc 1979;54:22-31.

${ }^{10}$ Gilbert JJ, Vintners HV. Cerebral amyloid angiopathy: incidence and complications in the aging brain. 1. Cerebral haemorrhage. Stroke 1983;14:915-23.

${ }^{11}$ Kalyan-Raman UP, Kalyan-Raman K. Cerebral amyloid angiopathy causing intracranial haemorrhage. Ann Neurol 1984;16:321-9.

${ }^{12}$ Ishii N, Nishihara Y, Horie A. Amyloid angiopathy and lobar cerebral haemorrhage. J Neurol Neurosurg Psychiatry 1984;47:1203-10.

${ }^{13}$ Cosgrove GR, Leblanc R, Meagher-Villemure K, Ethier R. Cerebral amyloid angiopathy. Neurology 1985; 35:625-31.

${ }^{14}$ Wilcock GK, Esiri MM. Plaques, tangles and dementia: a quantitative study. $J$ Neurol Sci 1982;56:343-56.

${ }^{15}$ Wilcock GK, Esiri MM, Bowen DM, Smith CCT. The nucleus basalis in Alzheimer's disease: cell counts and cortical biochemistry. Neuropathol Appl Neurobiol 1983;9:175-9.

${ }^{16}$ Chapel H, Esiri MM, Wilcock GK. Immunoglobulins and other proteins in the cerebrospinal fluid of patients with Alzheimer's disease. J Clin Pathol 1984;37:697-9.

${ }^{17}$ Hare M. Clinical check-list for diagnosis of dementia. $\mathrm{Br}$ Med J 1978;2:266-7.

${ }^{18}$ Hodkinson HM. Evaluation of a mental test score for assessment of mental impairment in the elderly. Age Ageing 1972;1:233-8.

${ }^{19}$ Cross RB. Demonstration of neurofibrillary tangles in paraffin sections-a quick and simple method using a modification of Palmgren's method. Med Lab Sci 1982;39:67-9.

${ }^{20}$ Glenner GG. Alzheimer's disease: multiple cerebral amyloidosis. Banbury Report, 15. Cold Spring Harbour Symposium on Biological Aspects of Alzheimer's disease. Cold Spring Harbor, New York 1983:137-44.

${ }^{21}$ Mandybur TI. The incidence of cerebral amyloid angiopathy in Alzheimer's disease. Neurology 1975;25:120-6.

${ }^{22}$ Mountjoy CQ, Tomlinson BE, Gibson PH. Amyloid and senile plaques and cerebral blood vessels. A semiquantitative investigation of a possible relationship. $J$ Neurol Sci 1982;57:89-103. 
${ }^{23}$ Torack RM. Congophilic angiopathy complicated by surgery and massive haemorrhage. Am J Pathol 1975;81:349-66.

${ }^{24}$ Morimatsu M, Shunsaku H, Muramatsu A, Yoshikawa M. Senile degenerative brain lesions and dementia. $J$ Am Geriat Soc 1975;23:390-406.

${ }^{25}$ Vintners HV, Gilbert JJ. Cerebral amyloid angiopathy: incidence and complications in the aging brain 2. The distribution of amyloid vascular changes. Stroke 1983;14:924-8.

${ }^{26}$ Powers JM, Schlaepfer WW, Willingham M, Hall BJ. An immunoperoxidase study of senile cerebral amyloidosis with pathogenetic considerations. J Neuropath Exp Neurol 1981;40:592-612.

${ }^{27}$ Cohen DH, Feiner H, Jensson O, Frangione B. Amyloid fibril in hereditary cerebral haemorrhage with amyloidosis is related to the gastroentero-pancreatic neuroendocrine protein, gamma trace. J Exp Med 1983;158:623-8.

${ }^{28}$ Grubb A, Jensson O, Gudmundsson G, Arnason A, Lotberg H, Malm J. Abnormal metabolism of a $\gamma$ trace alkaline microprotein. The basic defect in hereditary cerebral haemorrhage with amyloidosis. New Engl J Med 1984;311:1547-9. 